\title{
Cepharanthine hydrochloride inhibits the Wnt//-catenin/Hedgehog signaling axis in liver cancer
}

\author{
GUI-FENG SU ${ }^{1 *}$, ZE-XIU HUANG $^{1 *}$, DENG-LIANG HUANG ${ }^{2}$, PENG-XIAO CHEN $^{1,3}$, \\ YAO WANG $^{3,4}$ and YI-FEI WANG ${ }^{1,3}$
}

\begin{abstract}
${ }^{1}$ Guangdong Provincial Key Laboratory of Bioengineering Medicine, College of Life Science and Technology, Jinan University, Guangzhou, Guangdong 510632; ${ }^{2}$ Central Laboratory, Affiliated Hospital of Qinghai University, Xining, Qinghai 810001; ${ }^{3}$ Guangzhou Jinan Biomedicine Research and Development Center Co. Ltd., Guangzhou, Guangdong 510632; ${ }^{4}$ School of Biotechnology and Health Sciences, Wuyi University, Jiangmen, Guangdong 529020, P.R. China
\end{abstract}

Received October 30, 2019; Accepted February 4, 2022

DOI: 10.3892/or.2022.8294

\begin{abstract}
Cepharanthine, a biscoclaurine alkaloid isolated from the roots of Stephania cephalantha Hayata, has been reported to demonstrate antitumor activity across multiple cancer types; however, the mechanisms are still under investigation. High transcriptional responses by both the Hedgehog and Wnt pathways are frequently associated with specific human cancers, including liver cancer. To investigate whether these signaling pathways are involved in the pharmaceutical action of cepharanthine, we investigated Hedgehog and Wnt signaling in models of liver cancer treated with a semi-synthetic cepharanthine derivative, cepharanthine hydrochloride $(\mathrm{CH})$, in vitro and in vivo. By using MTT cytotoxic, scratch, Transwell, colony formation and flow cytometry assays, the pharmaceutical effect of $\mathrm{CH}$ was assessed. The compound was found to inhibit cellular proliferation and invasion, and promote apoptosis. Subsequent mechanistic investigations revealed that $\mathrm{CH}$ suppressed the Hedgehog/Gli1 signaling pathway by inhibiting Glil transcription and its transcriptional activity. $\mathrm{CH}$ also inhibited $\mathrm{Wnt} / \beta$-catenin signaling, and the pathway was found to be an upstream regulator of
\end{abstract}

Correspondence to: Professor Yi-Fei Wang, Guangdong Provincial Key Laboratory of Bioengineering Medicine, College of Life Science and Technology, Jinan University, 601 West Huangpu Avenue, Tianhe, Guangzhou, Guangdong 510632, P.R. China

E-mail: twang-yf@163.com

Dr Yao Wang, School of Biotechnology and Health Sciences, Wuyi University, 99 Yingbin Blvd. Middle, Pengjiang, Jiangmen, Guangdong 529020, P.R. China

E-mail: wangyao_1125@hotmail.com

*Contributed equally

Abbreviations: $\mathrm{CH}$, cepharanthine hydrochloride; Hh, Hedgehog; SMO, Smoothened; Gli, glioma-associated oncogene homolog

Key words: cepharanthine, Hedgehog, Wnt, $\beta$-catenin, liver cancer
Hedgehog signaling in CH-treated liver cancer cells. Finally, the antitumor effects of $\mathrm{CH}$ were demonstrated in an in vivo xenograft tumor model. Immunohistochemical analysis indicated that Gli1 protein levels were diminished in $\mathrm{CH}$-treated xenografts, compared with that noted in the controls. In summary, our results highlight a novel pharmaceutical antitumor mechanism of cepharanthine and provide support for $\mathrm{CH}$ as a clinical therapy for refractory liver cancer and other Wnt/Hedgehog-driven cancers.

\section{Introduction}

Liver cancer is one of the most common forms of carcinomas diagnosed worldwide. In recent years, the morbidity and mortality of liver cancer have steadily increased (1). In the early stages of liver cancer, patients are treated using either surgical resection of the carcinoma or liver transplantation. However, the early phase of liver cancer is often asymptomatic, which means that diagnosis mostly occurs at the later stages of the disease (2). For most liver cancer patients, chemotherapy remains the primary therapeutic strategy, of which sorafenib is the current first-line therapy. However, sorafenib exhibits limited efficacy, and long-term treatment with the drug results in little benefit to the patient's long-term survival. The latter of which is due to the development of drug resistance through multiple mechanisms $(3,4)$. Thus, new therapeutic methods that can effectively treat refractory liver cancer are urgently needed.

Hedgehog (Hh) signaling is a pathway that directs the development of embryonic cells in animals, from invertebrates to vertebrates. Hh induces the differentiation of endodermal progenitors into hepatocytes (5). The pathway is also reported to play a substantial role in the carcinogenesis and progression of liver cancer. Aberrant activation of $\mathrm{Hh}$ occurs in chronic liver damage and across various stages of liver cancer development (6). The central role of $\mathrm{Hh}$ in the development of liver cancer has resulted in a search for potential therapeutic targets to mitigate this pathway. Smoothened (SMO) and the glioma-associated oncogene homolog (Gli) family of zinc-finger transcription factors are both downstream effectors of Hh signaling. They are both regarded as important 
targets for cancer therapeutics. Gli activators bind to the GAC CACCCA motif to regulate transcription of GLI1, PTCH1, PTCH2, HHIP1, MYCN, CCND1, CCND2, BCL2, CFLAR, FOXF1, FOXL1, PRDM1 (BLIMP1), JAG2, GREM1, and Follistatin (7). Recently, we identified Rho guanine nucleotide exchange factor 16 (ARHGEF16) as a new downstream target of Gli2 (8). In recent years, a large number of small-molecule inhibitors targeting the $\mathrm{Hh}$ signaling pathway have been developed. Of these, vismodegib (GDC-0449) and sonidegib (LDE225) received FDA approval for the treatment of basal cell carcinoma, while glasdegib (PF-04449913) was approved for treating acute myeloid leukemia in combination therapy. However, acquired resistance to vismodegib was observed in clinical trials of the compound. At present, preclinical studies and clinical trials continue to evaluate the efficacy of $\mathrm{Hh}$ inhibitors across multiple types of cancer.

Over the past decade, several naturally occurring compounds capable of inhibiting the aberrant activation of Hh signaling have also been investigated for their preventative and therapeutic potential $(9,10)$. For example, berberine, cyclopamine, and vitamin D3 target SMO to directly inhibit $\mathrm{Hh}$ signaling, while glabrescione B acts via Gli1 (11-14). Curcumin, genistein and resveratrol also hold potential as Hh inhibitors and are currently under investigation (15). Natural compounds often target multiple signaling pathways, rather than acting as specific or direct modulators of individual signaling pathways. Therefore, the inhibitors of $\mathrm{Hh}$ signaling may function in a cell type-dependent manner. The mechanisms of these Hh inhibitors in certain cancers remain problematic, and additional natural compounds capable of inhibiting Hh signaling remain undiscovered.

Cepharanthine, a biscoclaurine alkaloid isolated from the roots of Stephania cephalantha Hayata, has been used clinically to treat radiation-induced leukopenia, alopecia, and snakebites for decades. It is not associated with any severe side effects (16). Cepharanthine has also been reported to possess antitumor activity in multiple types of cancer, including liver cancer (17-22). Cepharanthine acts to inhibit cellular proliferation and promote apoptosis. The mechanisms by which it does this are complex, and likely cell type-dependent. Mechanistic studies of cepharanthine suggest that the compound induces: the suppression of NF- $\kappa \mathrm{B}$ activity (23), chromatin condensation, nuclear fragmentation, JNK1/2 activation (24), upregulation of p21Waf1/Cip1, downregulation of cyclin A and Bcl-2, induction of reactive oxygen species (ROS) (25), and mitochondrial dysfunctions (26). However, more potential antitumor mechanisms of cepharanthine are still under investigation.

In the present study, cepharanthine hydrochloride $(\mathrm{CH})$, a semi-synthetic derivative of cepharanthine, was utilized to investigate the association of $\mathrm{CH}$ and the $\mathrm{Wnt} / \mathrm{Hh} / \mathrm{Gli1}$ signaling pathways for the treatment of liver cancer. This study may provide insight into the clinical potential of $\mathrm{CH}$ as an $\mathrm{Hh}$ signaling inhibitor for the treatment of liver cancer or other Hh-driven cancers.

\section{Materials and methods}

Cell culture. Hepatocellular carcinoma cell lines Huh7 and HepG2 were purchased from the Cell Bank of the Shanghai Biological Institute (Shanghai, China). Cells were cultured in
DMEM (41965120, Gibco) with $10 \%$ fetal bovine serum (FBS; 1027-106, Gibco; Thermo Fisher Scientific, Inc.) and $100 \mathrm{U} / \mathrm{ml}$ penicillin/streptomycin (15140163, Invitrogen; Thermo Fisher Scientific, Inc.). Both cell lines were incubated in a humidified incubator at $37^{\circ} \mathrm{C}$ with $5 \% \mathrm{CO}_{2}$. All cell lines were authenticated using STR method by a third-party testing organization.

Chemicals and antibodies. $\mathrm{CH}$, a semi-synthetic derivative of cepharanthine was developed by Guangzhou Jinan Biomedicine Research and Development Center Co. Ltd. Wnt signaling inhibitor IWR-1 (S7086) and Gli1 antagonist GANT61 (S8075) were both purchased from Selleck Chemicals.

Primary antibodies for Gli1 (\#2643), PARP (\#9532), GAPDH (\#2118), Snail (\#3879), c-myc (\#5605) and cyclin D1 (\#2978) were all purchased from Cell Signaling Technology (CST). Antibodies for Gli1 (ab92611), caspase 3 (NB100-56708), SMO (20787-1-AP) and $\beta$-catenin (sc-7963) were purchased from Abcam, NOVUS Biologicals, Proteintech and Santa Cruz Biotechnology, Inc., respectively.

Cell viability. Cells $(20,000)$ were seeded into $96-$-well plates and allowed to attach overnight. The following morning, the supernatant was discarded and replaced with the complete medium containing $0,5,10,20,40$ and $60 \mu \mathrm{M}$ of $\mathrm{CH}$. Cells were cultured at $37^{\circ} \mathrm{C}$ and $5 \% \mathrm{CO}_{2}$ for either 24 or $48 \mathrm{~h}$. Following this, $10 \mu 1$ of MTT (M2128, Sigma-Aldrich; Merck $\mathrm{KGaA}$ ) at a final concentration of $5 \mathrm{mg} / \mathrm{ml}$ was added and incubated for $4 \mathrm{~h}$ at $37^{\circ} \mathrm{C}$. The supernatant fraction was carefully discarded and $100 \mu \mathrm{l}$ DMSO was added to dissolve the water-insoluble MTT formazan. The optical density (OD) was subsequently measured using a wavelength of $570 \mathrm{~nm}$, and a microplate reader (Epoch, Bio-tek). The OD570 of the control cells was used to represent $100 \%$ viability.

Cell invasion assay. The invasive ability of the cells was evaluated using $6.5-\mathrm{mm}$ Transwell chambers $(8-\mu \mathrm{m}$ pore size, Corning Inc.). These chambers were pre-coated with $1 \mathrm{mg} / \mathrm{ml}$ Matrigel ${ }^{\circledR}$ Basement Membrane Matrix (Corning Inc.) according to the manufacturer's protocol. The cells $(4,000)$ were suspended in $200 \mu \mathrm{l}$ serum-free medium and seeded in the upper chambers. The wells under the chambers were filled with $600 \mu 1$ medium containing $10 \%$ FBS with or without $\mathrm{CH}$. After $48 \mathrm{~h}$, the residual cells in the top surface of the chambers were removed. The invading cells on the bottom were fixed with 4\% paraformaldehyde (P1110, Solarbio) and stained using $1 \%$ crystal violet. The cells were then photographed using the Leica DMi1 inverted microscope with a total magnification of $\mathrm{x} 100$.

Colony formation assay. Colony formation assays were undertaken by seeding Huh7 or HepG2 cells (4,000 cells/well) into 6-well plates. The cells were allowed to form colonies for 7-10 days before different concentrations of $\mathrm{CH}$ were added and incubated with the cells for an additional $72 \mathrm{~h}$. The medium was renewed every three days. Following this, the cells were washed with PBS, and fixed in $4 \%$ paraformaldehyde for 15 min. Fixed cells were then stained with $1 \%$ crystal violet for $15 \mathrm{~min}$ and then rinsed with distilled water. The colonies 
formed were photographed using the Leica DMil inverted microscope with a total magnification of $\mathrm{x} 40$.

Western blot analysis. The cells were lysed in RIPA buffer containing $50 \mathrm{mM}$ Tris (pH 7.4), $150 \mathrm{mM} \mathrm{NaCl}, 1 \% \mathrm{NP} 40$, $0.5 \%$ sodium deoxycholate and $0.1 \%$ SDS (P0013C, Beyotime Institute of Biotechnology). Total protein concentration was quantified using the BCA Protein Assay Kit (P0011, Beyotime Institute of Biotechnology). The lysates of equal protein concentrations (total $30 \mu \mathrm{g}$ protein) were separated using $8-12 \%$ sodium dodecyl sulfate-polyacrylamide gels and then transferred to PVDF membranes (ISEQ00010, Millipore). Next, 5\% skim milk was used to block the membranes before they were probed with the primary antibodies $(1: 1,000)$ and incubated at $4^{\circ} \mathrm{C}$ overnight on a shaker. The species-specific HRP-conjugated secondary antibodies $(1: 4,000)$ were incubated with the membranes for $1 \mathrm{~h}$ at room temperature. The immunoreactive bands were detected using an enhanced chemiluminescence kit (34580, Thermo Fisher Scientific, Inc.). GAPDH was used as a loading control.

Flow cytometry. CH-induced apoptosis was assessed by the detection of cells stained with Annexin V Alexa Fluor488/propidium iodide (PI) reagent (FXP022-050, 4A Biotech Co.) using a FACSCalibur flow cytometer (BD Biosciences). Flow cytometry was conducted in accordance with the manufacturer's protocol. In short, cells were cultured with various concentrations of $\mathrm{CH}$ for $24 \mathrm{~h}$ before being digested in EDTA-free trypsin, and collected by centrifugation at $800 \mathrm{x} \mathrm{g}$ for $5 \mathrm{~min}$. The cells were then washed with cold PBS before being resuspended by the mixture of binding buffer and Annexin-V-FITC. This mixture was then incubated for $5 \mathrm{~min}$ at room temperature and away from light. The mixture of binding buffer and PI was then added for an additional $15 \mathrm{~min}$. Apoptotic cells were subsequently detected using flow cytometry, and the data were analyzed using FlowJo v10 software (FlowJo LLC).

RNA extraction and real-time quantitative $(q) P C R$. Cells were treated with various concentrations of $\mathrm{CH}$ for $24 \mathrm{~h}$. Total RNA was extracted using Trizol reagent (15596-026, Invitrogen; Thermo Fisher Scientific, Inc.) according to the manufacturer's protocol. Briefly, the cells were harvested and soaked in Trizol at room temperature for $10 \mathrm{~min}$. The RNA was then precipitated using isopropanol before being rinsed with $75 \%$ ethanol and dissolved in RNAase-free water. The purity and concentration of the RNA sample were then assessed using an UV spectrophotometer (NanoPhotometer ${ }^{\circledR}$ P330, IMPLEN). Next, $1 \mu \mathrm{g}$ of RNA was used to reversely transcribe into cDNA with a PrimeScript RT reagent kit (RR047A, TaKaRa). The assay was performed in a Bio-Rad CFX96 RT-PCR systems (Bio-Rad Laboratories) using an SYBR Premix DimerEraser (RR091A, TaKaRa). The reaction conditions were as follows: pre-denaturation at $95^{\circ} \mathrm{C}$ for $30 \mathrm{sec} ; 40$ cycles of denaturation at $95^{\circ} \mathrm{C}$ for $5 \mathrm{sec}$; annealing and extension at $55^{\circ} \mathrm{C}$ for $30 \mathrm{sec}$. Levels of mRNA were normalized to the housekeeping gene, GAPDH, using the comparative $\mathrm{Cq}$ method. The sequences of the primers used are listed in Table I.

Dual-luciferase reporter assay. HepG2 cells were seeded in a 24-well culture plate. Plasmids of pGL3 basic or pGL3
Table I. Primer sequences for qPCR.

\begin{tabular}{lll}
\hline Gene name & & \multicolumn{1}{c}{ Primer sequence (5'-3') } \\
\hline GLI1 & Forward & CTACATCAACTCCGGCCAAT \\
& Reverse & CGGCTGACAGTATAGGCAGA \\
SMO & Forward & GGGAGGCTACTTCCTCATCC \\
& Reverse & GGCAGCTGAAGGTAATGAGC \\
PTCH1 & Forward & CTCTGGAGCAGATTTCCAAGG \\
& Reverse & TGCCGCAGTTCTTTTGAATG \\
GAPDH & Forward & GAGTCAACGGATTTGGTCGT \\
& Reverse & GACAAGCTTCCCGTTCTCAG
\end{tabular}

GLI1, glioma-associated oncogene homolog; SMO, smoothened; $P T C H 1$, patched 1; GAPDH, glyceraldehyde-3-phosphate dehydrogenase.

basic-ARHGEF16 $(0.75 \mu \mathrm{g})$ and pUB6/V5-HisB-Gli1 $(0.25 \mu \mathrm{g})$, mixed with $0.025 \mu \mathrm{g}$ pRL-TK-luc, were co-transfected into the cells using Lipofectamine ${ }^{\mathrm{TM}} 3000$ transfection reagent (L3000015, Thermo Fisher Scientific, Inc.). The ARHGEF16 gene is a downstream target of Gli2 (8). This was conducted in triplicate, according to the manufacturer's instructions. After a 48-h transfection, the cells were treated with different concentrations of $\mathrm{CH}$ for $6 \mathrm{~h}$. Cell lysates were extracted, and luciferase activity was measured using the Luciferase Report Assay System (E1910, Promega, Corp.).

Xenograft tumor assay. All animal experiments were performed in accordance with national ethical guidelines and following the approval (approval no. IACUC-20180904-05) from the Institutional Animal Care and Use Committee of Jinan University (Guangzhou, Guangdong, China). Briefly, 10 female BALB/c-nu mice (5-weeks-old, BW 17.3 $\pm 0.6 \mathrm{~g}$, Institute of Laboratory Animal Sciences, Beijing, China) were housed in a specific pathogen-free environment with a $12 \mathrm{~h} \mathrm{light} / 12 \mathrm{~h}$ dark cycle and constant temperature of $23^{\circ} \mathrm{C}$. All the mice were given a standard chow diet and sterilized water ad libitum. Huh7 cells $\left(510^{5}\right)$ resuspended in $200 \mu \mathrm{l}$ Matrigel/PBS $(6 \mathrm{mg} / \mathrm{ml})$ were injected subcutaneously into the flank of the mice. Tumors were allowed to grow until reaching approximately $100 \mathrm{~mm}^{3}$, before the mice were randomly assigned to either the control or the treatment group $(n=5$ mice per group). Mice received daily peritoneal injections of either $\mathrm{CH}(20 \mathrm{mg} / \mathrm{ml})$ dissolved in saline (purchased from the First Affiliated Hospital of Jinan University) or saline only for 12 days. Tumor sizes (long tumor diameter, L; short tumor diameter, S) and body weights were measured on alternate days. The tumor volume (V) was calculated using the formula $\mathrm{V}=1 / 2 \mathrm{xLxW}^{2}$. On day 13 , the mice were euthanized through cervical dislocation performing by experienced experimenters. We verified death by signs of no breathing and no corneal reflex. Their xenograft tumors and livers were collected and fixed in $4 \%$ paraformaldehyde for further analysis.

Immunohistochemistry assay. Fixed xenograft tumors and livers were embedded into a paraffin block and sliced into 3- $\mu$ m-thick sections. Paraffin sections were then de-waxed, 
rehydrated and incubated with $0.3 \% \mathrm{H}_{2} \mathrm{O}_{2}$ to block endogenous peroxidase activity. Following this, the sections were autoclaved in $10 \mathrm{mM}$ sodium citrate buffer $(\mathrm{pH}$ 6.0) for $15 \mathrm{~min}$, and then incubated with $10 \%$ goat serum for $30 \mathrm{~min}$. Tissue sections were then exposed to the primary Gli1 antibody (1:200) and incubated overnight. The next day, sections were rinsed with PBS and the slides were immersed in the HRP-conjugated secondary antibodies before 3,3'-diaminobenzidine (DAB) was added. The staining of the slides was then visualized and photographed using Nikon Ti-E microscopy (Tokyo, Japan). The German semiquantitative scoring method was adopted to score the expression level of Gli1 (27). Each specimen was assigned a score according to both the intensity of the staining $(0=$ no staining, not detected; $1=$ weak staining, light yellow; $2=$ moderate staining, yellowish-brown; $3=$ strong staining, brown) and the extent of cells stained $(0=$ no staining; $1=1-24 \%$ stained; $2=25-49 \%$ stained; $3=50-74 \%$ stained; $4=75-100 \%$ stained). The immunoreactive score of the stained cells was then calculated using the following equation: Total score=intensity score $\mathrm{x}$ extent score.

Staining scores were conducted based on observations by at least two independent investigators blinded to the treatment conditions.

Statistical analysis. All data consist of the results of at least three independent experiments. Statistical significance was determined by the Mann-Whitney $U$ test for nonparametric analysis of the scoring of Gli1 expression in xenograft tissue. Two-tailed Student's t-tests and one-way ANOVA were used to compare the results of other assays. For the luciferase assay, Scheffe's post hoc test was used to compare the differences between every 2 groups. For comparison among three groups, LSD's post hoc test was used. All data are presented as mean $\pm \mathrm{SD}$. The statistical differences are shown as ${ }^{*} \mathrm{P}<0.05$; ${ }^{* *} \mathrm{P}<0.01 ;{ }^{* * *} \mathrm{P}<0.001$, as indicated in the figures and legends.

\section{Results}

CH inhibits cellular function and induces the apoptosis of liver cancer cells. Cepharanthine hydrochloride $(\mathrm{CH})$ is a semi-synthetic derivative of cepharanthine, and its chemical structure is shown as Fig. 1A. Cell viability assays were conducted using Huh7 and HepG2 cells to assess the effect of $\mathrm{CH}$ on liver cancer. As shown in Fig. $1 \mathrm{~B}, \mathrm{CH}$ inhibited the growth of Huh7 and HepG2 in a dose-dependent manner. The half maximal inhibitory concentration $\left(\mathrm{IC}_{50}\right)$ values indicated that the inhibitory effect of $\mathrm{CH}$ was more evident in Huh7 cells than in HepG2 cells. However, no significant differences were observed between 24 and $48 \mathrm{~h}$ in these cells. To further investigate the effects of $\mathrm{CH}$ on cellular function of these liver cancer cells, Transwell and colony formation assays were performed. As shown in Fig. $1 \mathrm{C}$ and D, CH markedly inhibited the invasive and proliferative activities of both cell lines. Although the concentrations of $\mathrm{CH}$ used in the cell viability and colony formation assays were the same, the treatment durations in the two assays are different. The cells were treated with $\mathrm{CH}$ for 24 or $48 \mathrm{~h}$ in the viability assay, but $72 \mathrm{~h}$ in the colony formation assay. In addition, the different confluence of the cells before drug treatment was also another influencing factor. Note that the cleaved forms of apoptosis-related proteins poly(ADP-ribose) polymerase (PARP) and caspase 3 were increased in a dose-dependent manner in both Huh7 and HepG2 cells (Fig. 1E). It was difficult to obtain a clear band of cleaved caspase 3 in the Huh7 cells. We suppose that caspase 3 is not a sensitive marker of $\mathrm{CH}$-induced apoptosis in Huh7 cells. Flow cytometry was then used to assess apoptosis. As shown in Fig. 1F, significantly more apoptotic cells were observed in the $\mathrm{CH}$-treated groups, in particulary the groups treated with high concentrations of $\mathrm{CH}(10 \mu \mathrm{M}$ for Huh7 cells and $20 \mu \mathrm{M}$ for HepG2 cells). These results revealed that, consistent with previous reports of cepharanthine in liver cancer (24), $\mathrm{CH}$ functioned to suppress liver cancer in vitro.

CH regulates the Hh signaling pathway in liver cancer cells. The Hh pathway is involved in the development of liver cancer, and its downregulation has been shown to suppress the growth of various types of cancer (28). In the present study, it was investigated whether the effects of $\mathrm{CH}$ on liver cancer cells were due to the inhibition of the Hh pathway. First, the qPCR assay demonstrated that $\mathrm{CH}$ treatment downregulated the transcription of both GLII and SMO, two downstream effectors of Hh signaling (Fig. 2A). Moreover, PTCH1, the negative regulator of $\mathrm{Hh}$ signaling, was found to be slightly increased in the HepG2 cells. Protein levels of Gli1, SMO and Snail, a rapidly induced protein of Gli1, were reduced in both cell types in a concentration-dependent and time-dependent manner (Fig. 2B and C). To further verify the effect of $\mathrm{CH}$ on Hh signaling activation, a dual-luciferase reporter assay was used to detect the transcriptional regulatory activity of Gli1 in $\mathrm{CH}$-treated cells. HepG2 cells were used to perform this experiment given their transfection efficiency and capacity to cope with the burden of multiple plasmids. The use of lower $\mathrm{CH}$ concentrations avoided further cytotoxicity to the cells. As shown in Fig. 2D, $\mathrm{CH}$ reduced the transcription activity of Gli1 in HepG2 cells. These results suggested that $\mathrm{CH}$ was functioning as an inhibitor of Hh by suppressing the transcription and transcriptional activity of Glil in liver cancer cells.

CH inhibits upstream Wnt/ $\beta$-catenin signaling. To determine the mechanism by which $\mathrm{CH}$ regulates $\mathrm{Hh}$ signaling, another essential regulator of embryonic development and tissue homeostasis, Wnt signaling was assessed. Crosstalk between Wnt and Hh signaling has been reported in multiple types of cancer. Here, it was demonstrated that $\mathrm{CH}$ inhibited the Wnt co-activator, $\beta$-catenin, in addition to two of its targets, proto-oncogene c-myc and cyclin D1 in a concentration-dependent and time-dependent manner (Fig. 3A and B). Images of the immunofluorescence in liver cancer cells showed that $\beta$-catenin was mainly located in the nucleus and was diminished under $\mathrm{CH}$ treatment (Fig. 3C). The regulatory relationships of these signaling pathways were then assessed using the Wnt inhibitor, IWR-1, and the Gli1/2 antagonist, GANT61. When Wnt signaling was inhibited, as indicated by the diminished level of $\beta$-catenin proteins, Gli1 levels in the IWR-1-treated cells were also decreased (Fig. 3D). On the other hand, GANT61 did not affect the level of $\beta$-catenin proteins (Fig. 3E). This indicated that Wnt signaling was occurring upstream of $\mathrm{Hh}$ signaling, and $\mathrm{CH}$ was acting to inhibit the $\mathrm{Wnt} / \beta$-catenin/Hh signaling cascade in liver cancer cells. 
A

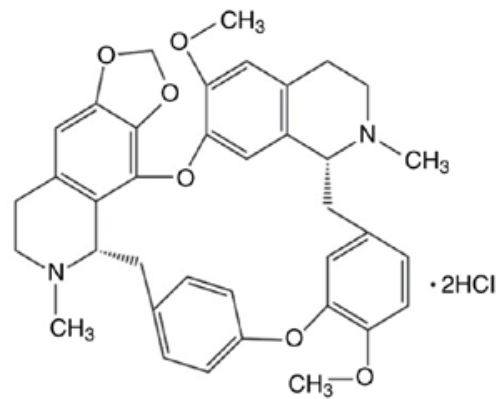

B
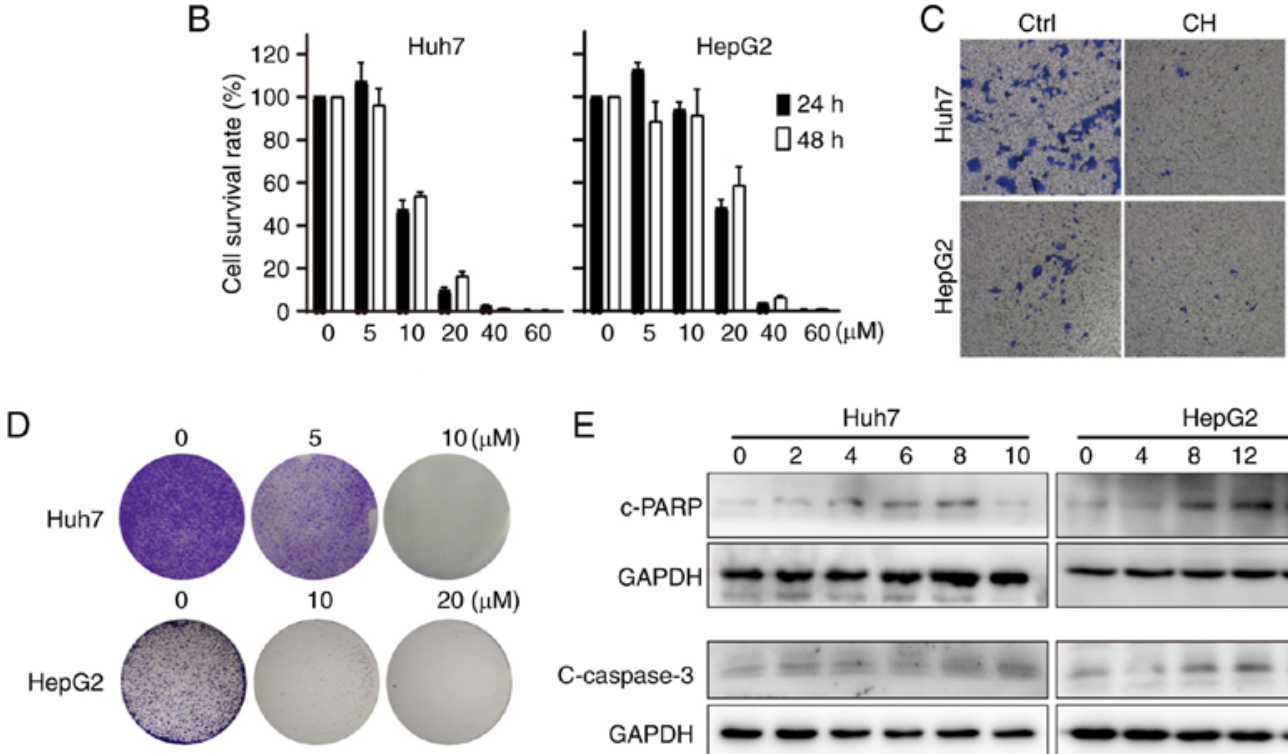

$E$
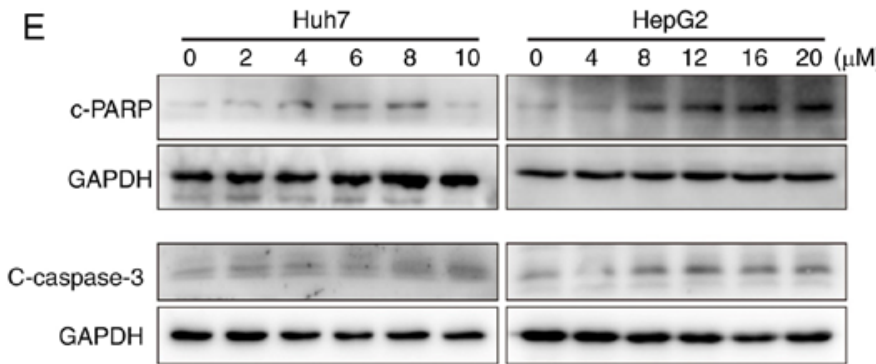

$\mathrm{F}$
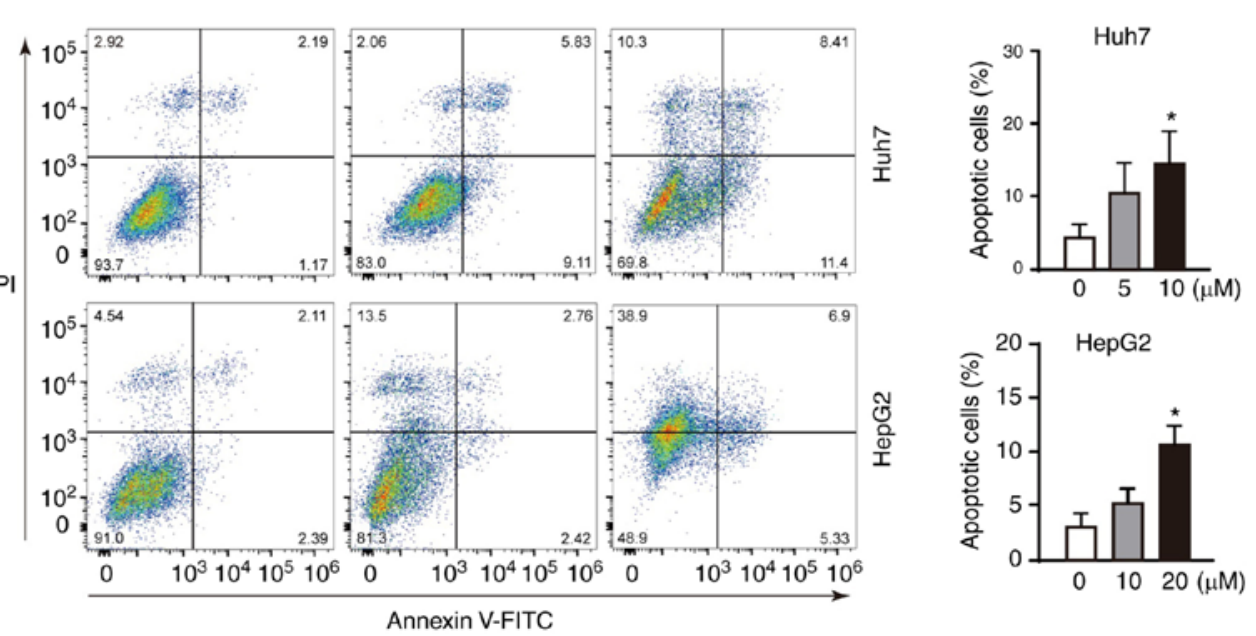

Figure 1. Cepharanthine hydrochloride $(\mathrm{CH})$ inhibits the cell functions of liver cancer cells. (A) Chemical structure of $\mathrm{CH}$. (B) Cell viability assays of $\mathrm{CH}$-treated liver cancer cells. Huh7 and HepG2 cells were exposed to different concentrations $(0-60 \mu \mathrm{M})$ of $\mathrm{CH}$ for 24 and 48 h. Cell viability was detected using the MTT method. (C) Transwell assay. Transwell chambers were precoated with $1 \mathrm{mg} / \mathrm{ml}$ Matrigel, and 4,000 cells were suspended in $200 \mu 1$ DMEM with no FBS and seeded in the upper chamber. The lower well was filled with DMEM containing 10\% FBS in the presence or absence of $\mathrm{CH}$ (Huh7: $10 \mu \mathrm{M}$; HepG2: $20 \mu \mathrm{M}$ ) for $48 \mathrm{~h}$. The cells that invaded the outer side of the chamber bottom were fixed and stained with crystal violet, and then photographed (x100). (D) Colony formation assay. Cells (4,000 cells per well) were seeded into a 6 -well plate. The cells were allowed to form colonies for 7-10 days before different concentrations of $\mathrm{CH}$ were added and incubated with the cells for an additional $72 \mathrm{~h}$. Following fixation with $4 \%$ paraformaldehyde, the cells were stained with $1 \%$ crystal violet and photographed (x40). (E) Detection of apoptotic proteins using western blot analysis. Cells were treated with increasing concentrations of $\mathrm{CH}$. The lysates were subjected to western blotting and probed with primary and corresponding species-specific secondary antibodies, as indicated. (F) Flow cytometry assay. Cells were treated with different concentrations of $\mathrm{CH}$ for $24 \mathrm{~h}$, and then stained using Annexin $\mathrm{V}$ and PI reagents for flow cytometric analysis. Data are shown as mean $\pm \mathrm{SD}$ of three independent experiments. " $\mathrm{P}<0.05$, compared to the untreated group. c-, cleaved; PARP, poly(ADP-ribose) polymerase.

CH inhibits tumorigenesis through Hh signaling in vivo. We next examined the antitumor activity of $\mathrm{CH}$ in vivo. Xenograft mouse models were established by injecting Huh7 cells subcutaneously (s.c.) into the flank of nude mice. Xenografts were allowed to grow to $\sim 100 \mathrm{~mm}^{3}$ before animals were treated with daily intraperitoneal (i.p) injections of $\mathrm{CH}$ or saline for 12 days (Fig. 4A). No significant difference in body weight was observed between the two groups, indicating that $\mathrm{CH}$ 

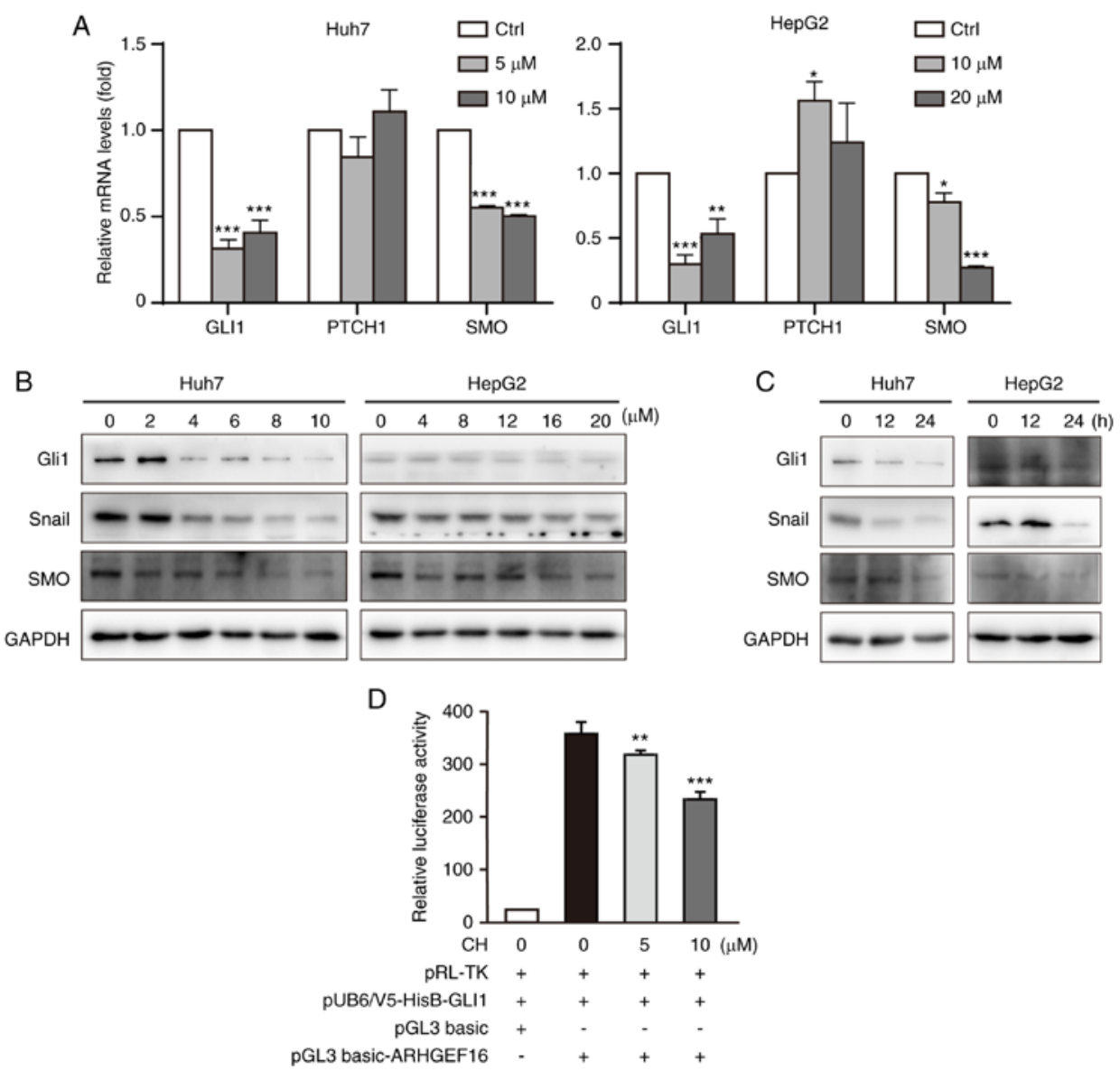

Figure 2. Cepharanthine hydrochloride $(\mathrm{CH})$ inhibits Hedgehog $(\mathrm{Hh})$ signaling. (A) Real-time quantitative PCR assay. Cells were treated with different concentrations of $\mathrm{CH}$ for $24 \mathrm{~h}$. Total RNA was extracted by Trizol before undergoing reverse transcription into cDNA. The mRNA levels were normalized to levels of the housekeeping gene GAPDH. (B) Proteins of Hh signaling respond to different concentrations of CH. Cells were treated with increasing concentrations of $\mathrm{CH}$ for $24 \mathrm{~h}$. The lysates were subjected to western blotting and probed with primary and corresponding species-specific secondary antibodies, as indicated. ${ }^{*} \mathrm{P}<0.05,{ }^{* *} \mathrm{P}<0.01,{ }^{* * *} \mathrm{P}<0.001$, significance reported relative to the control (Ctrl). (C) Proteins of Hh signaling across the time course of $\mathrm{CH}$ treatment. Cells were treated with $\mathrm{CH}$ (10 $\mu \mathrm{M}$ for Huh7 cells; $20 \mu \mathrm{M}$ for HepG2 cells) for 12 or $24 \mathrm{~h}$. The lysates were subjected to western blotting and probed with primary and corresponding species-specific second antibodies, as indicated. (D) Dual-luciferase assays. HepG2 cells were co-transfected with pRL-TK-luc, pUB6/V5-HisB-Gli1, pGL3 basic/basic-ARHGEF16 plasmids for $48 \mathrm{~h}$. Following this, cells were treated with $\mathrm{CH}(5$ or $10 \mu \mathrm{M})$ for an additional $6 \mathrm{~h}$. Luciferase activity was measured in the cell lysates using the Luciferase Report Assay System. ${ }^{* * *} \mathrm{P}<0.01,{ }^{* * * *} \mathrm{P}<0.001$, significance reported relative to the control (Ctrl). GLI1, glioma-associated oncogene homolog 1; PTCH1, patched 1; SMO, smoothened.

Table II. The maximum long (L) and short (S) tumor diameters (in $\mathrm{mm}$ ).

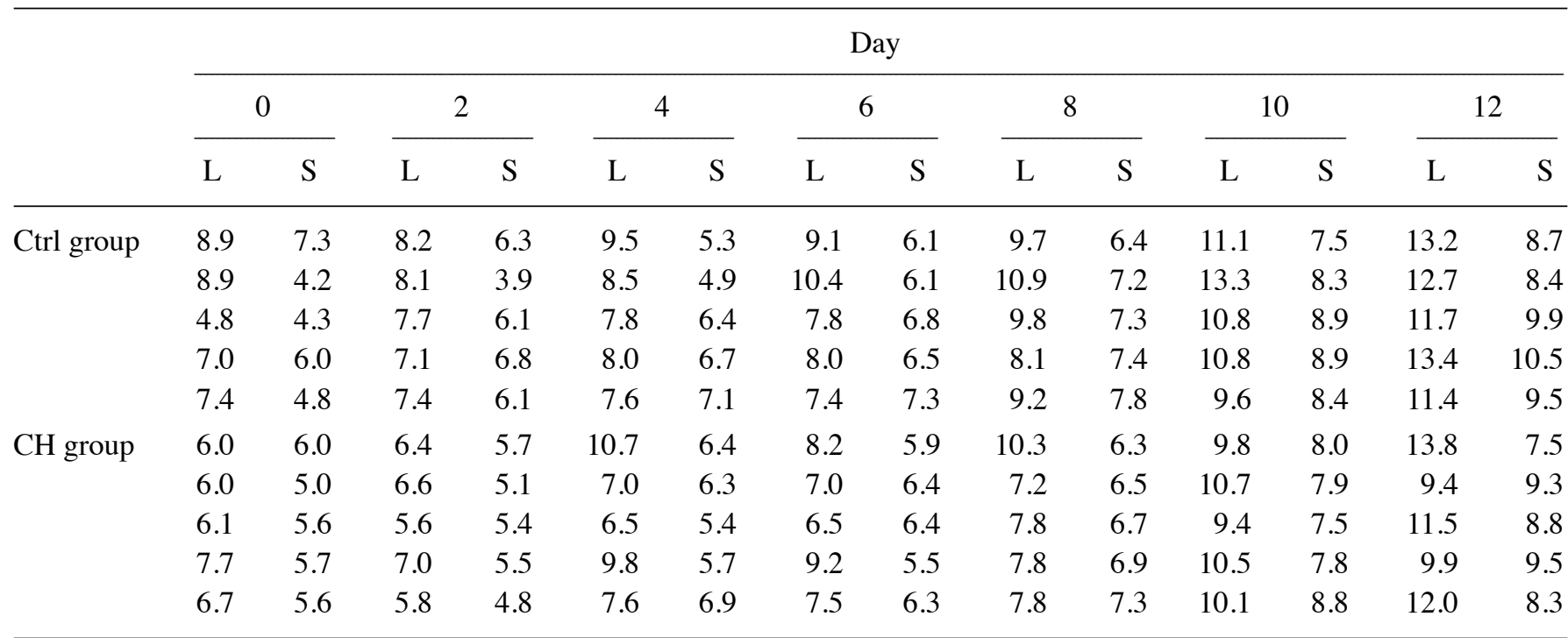

$\mathrm{CH}$, cepharanthine hydrochloride. 
A

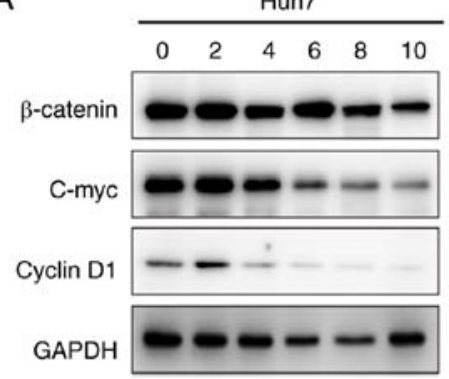

HepG2

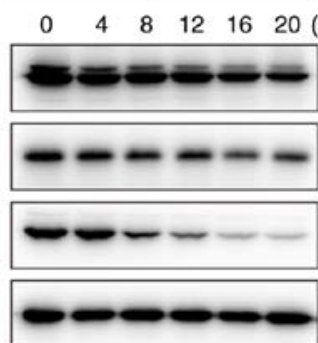

B

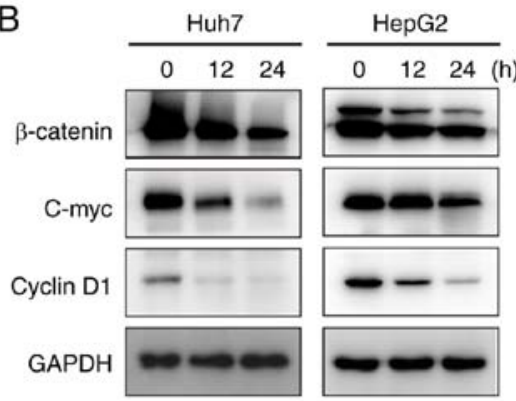

C

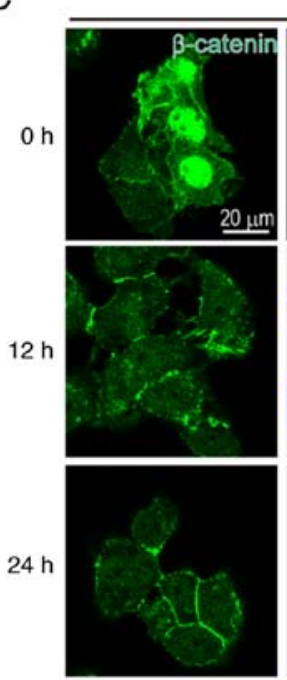

Huh7
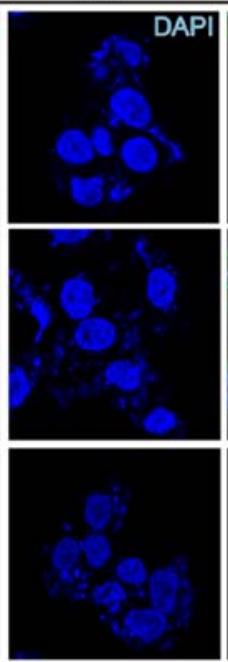
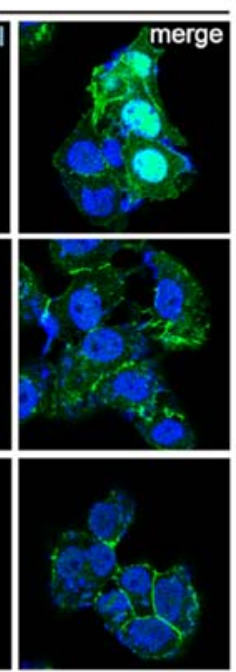

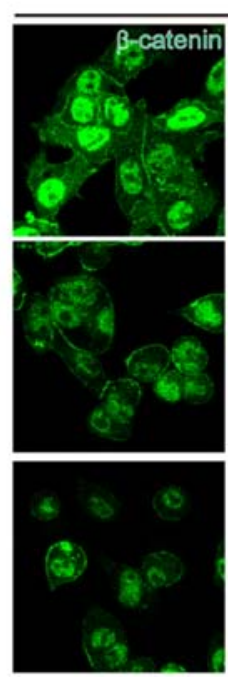

HepG2

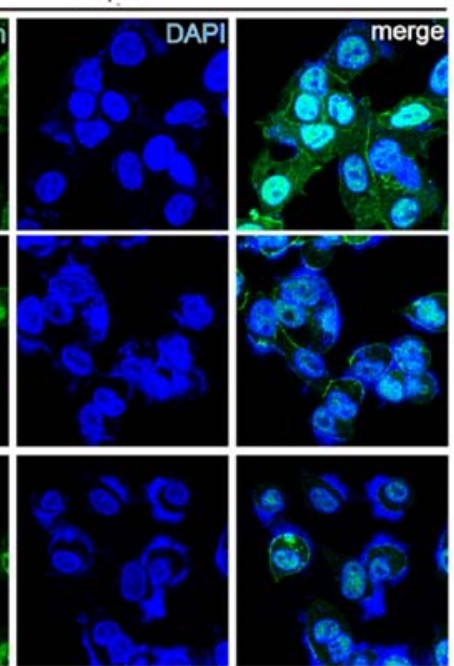

E

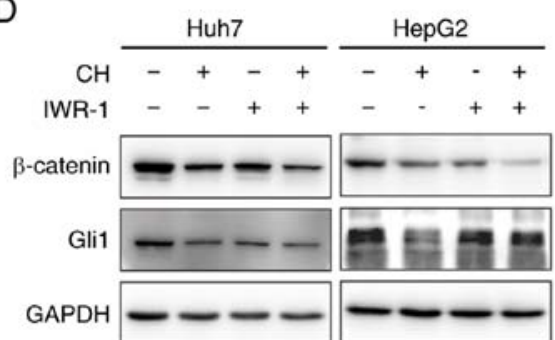

\begin{tabular}{|c|c|c|c|c|c|c|c|}
\hline \multirow[b]{2}{*}{$\mathrm{CH}$} & \multicolumn{3}{|c|}{ Huh7 } & \multicolumn{4}{|c|}{ HepG2 } \\
\hline & - & + & + & - & & - & + \\
\hline ANT61 & - & $-\quad+$ & + & - & - & + & + \\
\hline
\end{tabular}

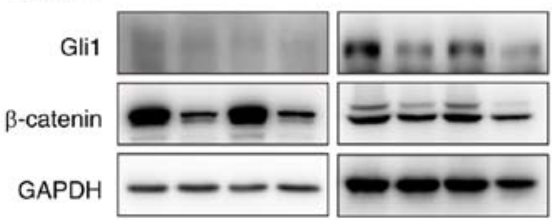

Figure 3. Cepharanthine hydrochloride $(\mathrm{CH})$ inhibits the Wnt signaling pathway. (A) Proteins of Wnt signaling respond to different concentrations of $\mathrm{CH}$. Cells were treated with increasing concentrations of $\mathrm{CH}$ for $24 \mathrm{~h}$. The lysates were subjected to western blotting and probed with primary and corresponding species-specific second antibodies, as indicated. (B) Proteins of Wnt signaling across the time course of $\mathrm{CH}$ treatment. Cells were treated with $\mathrm{CH}$ (10 $\mu \mathrm{M}$ for Huh7 cells; $20 \mu \mathrm{M}$ for HepG2 cells) for either 12 or $24 \mathrm{~h}$. Cell lysates were then subjected to western blotting and probed with primary and corresponding species-specific second antibodies, as indicated. (C) Immunofluorescence assay of intracellular $\beta$-catenin in the liver cells. Cells were treated with $\mathrm{CH}$ (Huh7: $10 \mu \mathrm{M}$; HepG2: $20 \mu \mathrm{M}$ ) for 12 or $24 \mathrm{~h}$. Immunofluorescence of $\beta$-catenin (green) and DAPI (blue) were merged. (D) Inhibition of Wnt signaling suppressed Gli1 proteins. Cells were treated with $\mathrm{CH}$ (Huh7: $10 \mu \mathrm{M}$; HepG2: $20 \mu \mathrm{M}$ ) or IWR-1 (Huh7: $10 \mu \mathrm{M}$; HepG2: $20 \mu \mathrm{M}$ ) for $24 \mathrm{~h}$. Gli1 protein expression was then detected via western blotting method. (E) Inhibition of Hh signaling did not affect proteins of the Wnt signaling pathway. Cells were treated with $\mathrm{CH}$ (Huh7: $10 \mu \mathrm{M}$; HepG2: $20 \mu \mathrm{M}$ ) or GANT61 (Huh7: $10 \mu \mathrm{M}$; HepG2: $20 \mu \mathrm{M}$ ) for $24 \mathrm{~h}$. Protein expression of $\beta$-catenin was then detected via western blotting method. Gli1, glioma-associated oncogene homolog 1.

was well-tolerated by these mice (Fig. 4B). In the control mice, xenograft growth increased dramatically from the 6th day after saline administration. Xenograft growth rates in the $\mathrm{CH}$-treated group were slower than those observed in the control group. This difference became significant at the end of the experiment (Fig. 4C). The maximum long (L) and short (S) tumor diameters are shown in Table II. Following the sacrifice of these animals at the end of the study, the weights of the xenografts in the $\mathrm{CH}$-treated animals were found to be decreased compared with those in the control group (Fig. 4D). Many chemicals are known to induce hepatotoxicity and subsequently increase the weight of the liver; as such, liver weights were also compared across treatment groups. No significant differences in liver weights were observed, suggesting that the administration of $\mathrm{CH}$ did not induce hepatotoxicity during the 12-day treatment in these nude mice (Fig. 4E). Hematoxylin and eosin staining of the livers confirmed the safety of $\mathrm{CH}$ (data not shown). Xenograft levels of Gli1 were assessed using immunohistochemistry assay. This analysis demonstrated that Gli1 protein expression was suppressed in the $\mathrm{CH}$-treated xenografts compared with the saline-treated xenografts (Fig. 4F and G). The median score of the control group was 6 [interquartile range; IQR (3.75-8.25)], while the median score of the $\mathrm{CH}$-treated group was 3 [interquartile range; IQR 


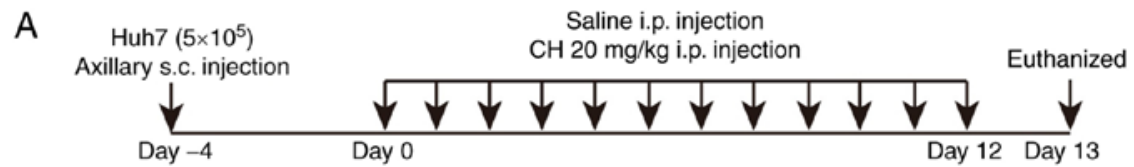

B

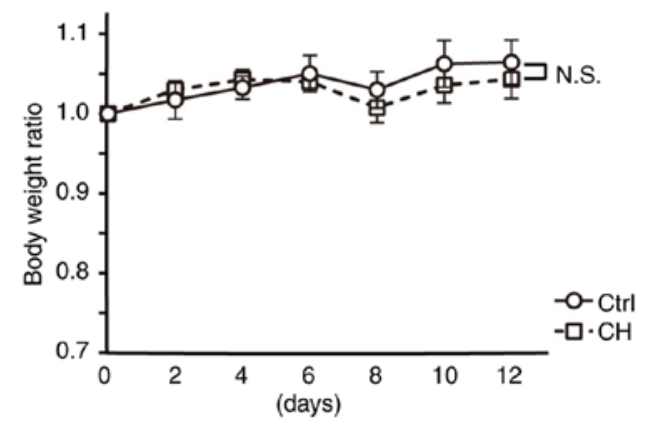

D

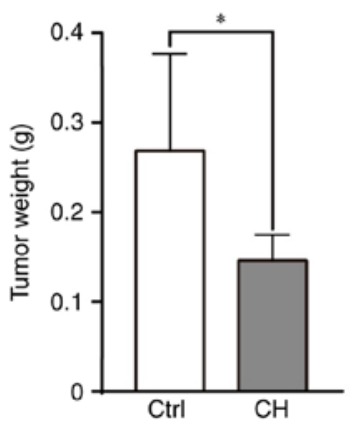

$\mathrm{E}$

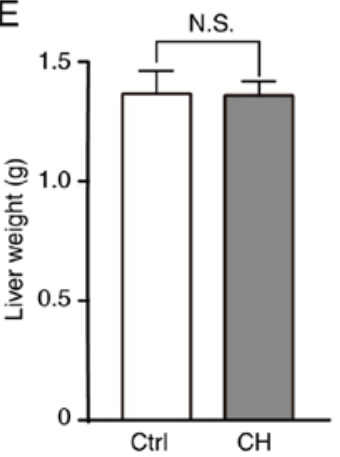

$\mathrm{C}$

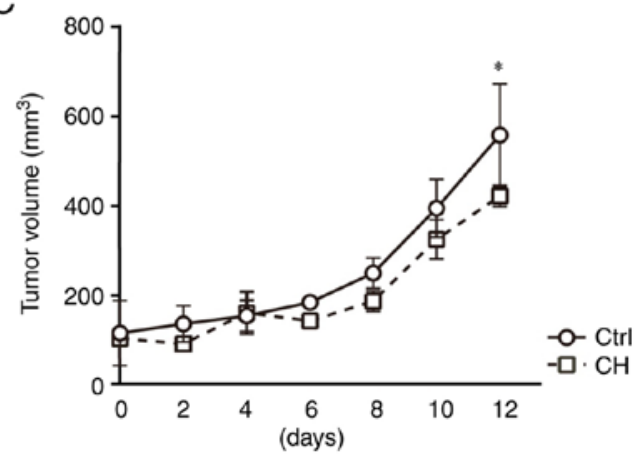

$\mathrm{F}$

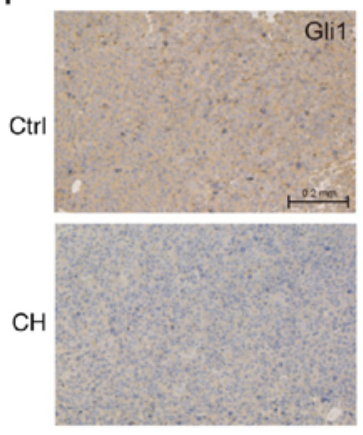

$\mathrm{G}$

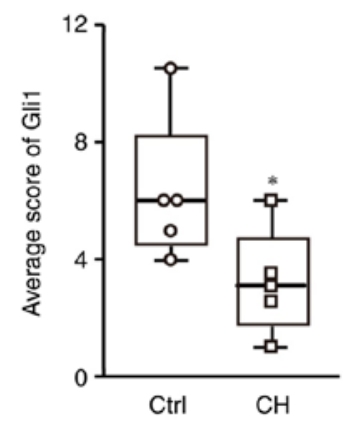

Figure 4. Cepharanthine hydrochloride $(\mathrm{CH})$ slows liver cancer xenograft growth rates by inhibiting Hedgehog (Hh) signaling in vivo. (A) Schedule of the in vivo experiments. (B) The body weights of the nude mice. (C) Xenograft growth curves. (D) Xenograft weights. (E) Liver weights. (F) Representative immunohistochemical images of Gli1 expression in xenograft tissue. $(\mathrm{G})$ Scoring of Glil expression in xenograft tissue. $\mathrm{Z}=-2.009$, $\mathrm{P}=0.045$. ${ }^{*} \mathrm{P}<0.05$, significance reported relative to the control (Ctrl); N.S., not significant. Gli1, glioma-associated oncogene homolog 1.

(1.75-4.75)]. Taken together, these results revealed that $\mathrm{Hh}$ signaling may be an essential mechanism by which $\mathrm{CH}$ exerts its antitumor activity in liver cancer cells.

\section{Discussion}

In the present study, we revealed a novel antitumor mechanism of cepharanthine hydrochloride $(\mathrm{CH})$ in cell and animal models of liver cancer. This was achieved by suppressing the Hedgehog $(\mathrm{Hh})$ signaling pathway and its upstream signaling via $\mathrm{Wnt} / \beta$-catenin. In vitro and in vivo experiments verified each other. The results propose the application of $\mathrm{CH}$ in Wnt/Hedgehog-driven tumors, including medulloblastoma, basal cell carcinoma, glioblastoma, leukemia, lymphoma, and esophageal, lung, gastric, pancreatic, colorectal, prostate, ovarian, and liver cancer (29). Therefore, the present study findings may contribute to the drug development of cepharanthine for tumor therapy.

Dozens of compounds capable of inhibiting Hh signaling have been identified. These molecules target several key steps in the $\mathrm{Hh}$ activation process. Most $\mathrm{Hh}$ pathway antagonists target smoothened (SMO); however, SMO is susceptible to mutation and is a frequent contributor to the development of chemoresistance. Therefore, compounds that target the cascade downstream of SMO may represent a more promising therapeutic strategy. As with SMO, multiple compounds have been identified as either direct or indirect inhibitors of glioma-associated oncogene homolog (Gli) transcription. One such compound is GANT61. GANT61 is a highly efficient antagonist that acts by binding to the zinc finger regions of Gli1 and Gli2. Several preclinical studies have demonstrated that GANT61 has antitumor activity in a number of cancer types, including acute myeloid leukemia, rhabdomyosarcoma, neuroblastoma, melanoma, and cancers of the lung, breast, colon, prostate, and pancreas (30). Despite its broad spectrum of antitumor activity, the instability of GANT61 at a physiological $\mathrm{pH}$ results in the compound hydrolyzing into an inactive benzaldehyde species (31). Arsenic trioxide (ATO) is another Gli inhibitor and is known for its use in acute promyelocytic leukemia (32). In recent preclinical studies and clinical trials, ATO has shown promising antitumor effects in several solid tumors, such as breast, lung, glioma, pancreas, and liver cancer $(30,33,34)$. ATO is recommended for clinical use in situations where conventional chemotherapies cannot be used. Although Gli is a promising antitumor target, synthetic compounds targeting Gli have been reported to result in frequent adverse events and show low bioavailability in human patients. A number of existing, naturally derived compounds have shown promise as Gli inhibitors. These clinically approved therapies have better bioavailability, fewer toxic side effects, and an existing clinical trial dataset. They also have the ability to inhibit the Hh pathway via multiple 
targets. Metformin is a good example of such a compound, and has been shown to inhibit Hh signaling by suppressing sonic hedgehog, SMO, Patched, and Gli1 expression in various cancer cells (35-37). Cepharanthine, a biscoclaurine alkaloid isolated from the roots of Stephania cephalantha Hayata, is another example. This compound has been used in Japan since the 1950s to treat multiple acute and chronic diseases. Cepharanthine has also recently been reported to possess antitumor activity via a number of mechanisms; these oncogenic pathways or signaling nodes include $\mathrm{NF}-\kappa \mathrm{B}$, multidrug resistance protein 1 (MRP1), PI3K/Akt, AMPK, JNK1/2, and DNA damage repair (22). Here, the present study revealed for the first time that cepharanthine, and its semi-synthetic derivative $\mathrm{CH}$, are also able to suppress oncogenesis by inhibiting the $\mathrm{Hh}$ signaling pathway.

The Wnt $/ \beta$-catenin pathway and the Hh signaling pathway are both correlated with the presence and progression of drug resistance in liver cancer, and crosstalk between these pathways has been frequently reported (38). More specially, the Hh transcription factor Glil is reported to induce secreted frizzled-related protein 1 (sFRP-1), which is a negative regulator of Wnt signaling. Thus, sFRP-1 inhibits the transduction of Wnt signaling by interacting selectively and non-covalently with both the Wnt protein and the Frizzled receptors $(39,40)$. Therefore, the inhibition of Hh signaling using a Gli antagonist may act to activate Wnt signaling via the upregulation of sFRP-1 in some cancers. This indicates that strategies targeting Hh signaling only, may not achieve the desired therapeutic effect. Co-activation of both $\mathrm{Hh}$ and Wnt pathways is associated with earlier recurrence and shorter overall survival times in patients with triple-negative breast cancer in a cohort study (41). Therefore, the findings that $\mathrm{CH}$ inhibits Wnt/ $\beta$-catenin signaling and Hh signaling simultaneously highlights its therapeutic potential not only in liver cancer, but also in other $\mathrm{Wnt} / \beta$-catenin and $\mathrm{Hh}$ associated cancers.

According to the literature, the regulatory relationship of Hh and Wnt signaling pathways remains controversial. In the present study, it was found that $\mathrm{Wnt} / \beta$-catenin functions upstream of Hh signaling in the two liver cancer cell lines Huh7 and HepG2. The antagonist of Wnt (IWR-1) reduced Gli1 proteins; however, the Hh inhibitor GANT61 was not found to affect the levels of the $\beta$-catenin protein. Therefore, the suppression of Hh signaling may be the major downstream effect of the $\mathrm{CH}$-mediated inactivation of $\mathrm{Wnt} / \beta$-catenin signaling and the diminished transcription of Gli1. It should also be noted that combined treatment with $\mathrm{CH}$ and IWR-1 exhibited synergistic effects on the suppression of $\beta$-catenin protein levels. As such, $\mathrm{CH}$ may have potential as an adjuvant drug for Wnt inhibitors in cases where the inhibition of Wnt signaling may be beneficial. Unlike Hh signaling, elevated Wnt signaling does not correlate with reduced patient survival in some types of cancer (42). However, Wnt signaling cannot be targeted using a single universal strategy, but rather it remains reliant on personalized clinical decision-making.

Wnt signaling is read out through total $\beta$-catenin levels, which are highly cell-type dependent. The effect of $\mathrm{CH}$ on cancers mediated by Wnt signaling (nuclear $\beta$-catenin levels, endogenous gene expression) should thus be assessed on a cancer-by-cancer basis. The $\beta$-catenin protein binds to a broad spectrum of transcription factors allowing it to modulate multiple downstream biological processes. With the exception of the nuclear messenger for Wnt signaling, $\beta$-catenin acts as the core link between cadherins and the cytoskeleton. Therefore, the effect of $\mathrm{CH}$ on tumor cell migration and invasion may rely on a diminished $\beta$-catenin response.

The antitumor effect of cepharanthine was demonstrated in the case of a patient suffering from multiple myeloma and showing no respond to preceding chemotherapy, who coincidently received therapy with cepharanthine due to thrombocytopenia. The case showed a marked reduction of tumor load. This is the only reported clinical case, to the best of our knowledge, that has demonstrated antitumor effect of cepharanthine (43). Since then, several in vivo studies were performed using xenograft animal models to research the pharmaceutical effect of cepharanthine on cancers, including lung cancer, breast cancer, and oral squamous cell carcinoma $(18,44,45)$. In these studies, the doses of cepharanthine varied from 20 to $50 \mathrm{mg} / \mathrm{kg}$, and were administered over experiments lasting between 21 and 46 days. Significantly, in these studies, cepharanthine alone did not demonstrate any marked antitumor effects. However, when it was used as an adjuvant, cepharanthine enhanced the antitumor activity of both chemotherapy and radiation therapy. In our liver cancer mouse model, $\mathrm{CH}$ monotherapy of $20 \mathrm{mg} / \mathrm{kg} /$ day showed significance when calculating tumor sizes on the 12th day. However, the capacity of $\mathrm{CH}$ to inhibit tumors seemed to be limited via an unknown mechanism. The underlying mechanisms inhibiting the antitumor effects of $\mathrm{CH}$ thus require additional research. These investigations would also help to identify which precise combination of therapeutic strategies incorporating $\mathrm{CH}$ would provide the greatest benefit as an antitumor therapeutic.

In conclusion, the present study identified that the semi-synthetic cepharanthine derivative $\mathrm{CH}$ inhibits $\mathrm{Hh}$ signaling in liver cancer cells. The newly described antitumor mechanism-of-action of $\mathrm{CH}$ provides further support for its application in cancer therapy.

\section{Acknowledgements}

Plasmids for the dual-luciferase assay were kind gifts from Professor Shi-Wen Luo of Nanchang University.

\section{Funding}

This work was supported by the Natural Science Foundation of Guangdong Province (grant no. 2018030310401) and the China Postdoctoral Science Foundation (grant no. 2017M622922).

\section{Availability of data and materials}

The datasets used and/or analyzed during the current study are available from the corresponding authors on reasonable request.

\section{Authors' contributions}

GFS carried out the experiments, visualization, and preparation for the experiments. ZXH carried out the experiments and preparation of the experiments. DLH designed the study methodology and carried out the experiments. PXC conducted the 
preparation and designed the methodology used in the experiments. YW was responsible for the conceptualization of the research design, methodology, data curation, formal analysis, funding acquisition, experiments, visualization, and writing of the original draft. YFW was the project administration in charge of the resource acquisition, validation of the data and supervision. All authors read and approved the manuscript and agree to be accountable for all aspects of the research in ensuring that the accuracy or integrity of any part of the work are appropriately investigated and resolved.

\section{Ethics approval and consent to participate}

All animal experiments were performed in accordance with national ethical guidelines and with approval (approval no. IACUC-20180904-05) from the Institutional Animal Care and Use Committee of Jinan University (Guangzhou, Guangdong, China).

\section{Patient consent for publication}

Not applicable.

\section{Competing interests}

The authors declare that they have no competing interests.

\section{References}

1. Siegel RL, Miller KD and Jemal A: Cancer statistics, 2018. CA Cancer J Clin 68: 7-30, 2018

2. Daher S, Massarwa M, Benson AA and Khoury T: Current and future treatment of hepatocellular carcinoma: An updated comprehensive review. J Clin Transl Hepatol 6: 69-78, 2018.

3. Nishida N, Kitano M, Sakurai T and Kudo M: Molecular mechanism and prediction of sorafenib chemoresistance in human hepatocellular carcinoma. Dig Dis 33: 771-779, 2015.

4. Niu L, Liu L, Yang S, Ren J, Lai PBS and Chen GG: New insights into sorafenib resistance in hepatocellular carcinoma: Responsible mechanisms and promising strategies. Biochim Biophys Acta Rev Cancer 1868: 564-570, 2017.

5. Della Corte CM, Viscardi G, Papaccio F, Esposito G, Martini G, Ciardiello D, Martinelli E, Ciardiello F and Morgillo F: Implication of the Hedgehog pathway in hepatocellular carcinoma. World J Gastroenterol 23: 4330-4340, 2017.

6. Che L, Yuan YH, Jia J and Ren J: Activation of sonic hedgehog signaling pathway is an independent potential prognosis predictor in human hepatocellular carcinoma patients. Chin J Cancer Res 24: 323-331, 2012.

7. Katoh Y and Katoh M: Hedgehog target genes: Mechanisms of carcinogenesis induced by aberrant hedgehog signaling activation. Curr Mol Med 9: 873-886, 2009.

8. Huang D, Wang Y, Xu L, Chen L, Cheng M, Shi W, Xiong H, Zalli D and Luo S: GLI2 promotes cell proliferation and migration through transcriptional activation of ARHGEF16 in human glioma cells. J Exp Clin Cancer Res 37: 247, 2018.

9. Mayank and Jaitak V: Molecular docking study of natural alkaloids as multi-targeted hedgehog pathway inhibitors in cancer stem cell therapy. Comput Biol Chem 62: 145-154, 2016.

10. Drenkhahn SK, Jackson GA, Slusarz A, Starkey NJ and Lubahn DB: Inhibition of hedgehog/Gli signaling by botanicals: A review of compounds with potential hedgehog pathway inhibitory activities. Curr Cancer Drug Targets 13 580-595, 2013

11. Wang J, Peng Y, Liu Y, Yang J, Ding N and Tan W: Berberine, a natural compound, suppresses Hedgehog signaling pathway activity and cancer growth. BMC Cancer 15: 595, 2015.

12. Chen JK, Taipale J, Cooper MK and Beachy PA: Inhibition of Hedgehog signaling by direct binding of cyclopamine to Smoothened. Genes Dev 16: 2743-2748, 2002.
13. Bijlsma MF, Peppelenbosch MP and Spek CA: (Pro-)vitamin $\mathrm{D}$ as treatment option for hedgehog-related malignancies. Med Hypotheses 70: 202-203, 2008.

14. Infante P, Mori M, Alfonsi R, Ghirga F, Aiello F, Toscano S, Ingallina C, Siler M, Cucchi D, Po A, et al: Gli1/DNA interaction is a druggable target for Hedgehog-dependent tumors. EMBO J 34: 200-217, 2015.

15. Bao C, Kramata P, Lee HJ and Suh N: Regulation of hedgehog signaling in cancer by natural and dietary compounds. Mol Nutr Food Res: 62, 2018. doi: 10.1002/mnfr.201700621.

16. Rogosnitzky M and Danks R: Therapeutic potential of the biscoclaurine alkaloid, cepharanthine, for a range of clinical conditions. Pharmacol Rep 63: 337-347, 2011.

17. Zhou P, Zhang R, Wang Y, Xu D, Zhang L, Qin J, Su G, Feng Y, Chen $\mathrm{H}$, You S, et al: Cepharanthine hydrochloride reverses the mdr1 (P-glycoprotein)-mediated esophageal squamous cell carcinoma cell cisplatin resistance through JNK and p53 signals. Oncotarget 8: 111144-111160, 2017.

18. Tang ZH, Cao WX, Guo X, Dai XY, Lu JH, Chen X, Zhu H and $\mathrm{Lu}$ JJ: Identification of a novel autophagic inhibitor cepharanthine to enhance the anti-cancer property of dacomitinib in non-small cell lung cancer. Cancer Lett 412: 1-9, 2017.

19. Gao S, Li X, Ding X, Qi W and Yang Q: Cepharanthine induces autophagy, apoptosis and cell cycle arrest in breast cancer cells. Cell Physiol Biochem 41: 1633-1648, 2017.

20. Harada K, Ferdous T, Itashiki Y, Takii M, Mano T, Mori Y and Ueyama Y: Cepharanthine inhibits angiogenesis and tumorigenicity of human oral squamous cell carcinoma cells by suppressing expression of vascular endothelial growth factor and interleukin-8. Int J Oncol 35: 1025-1035, 2009.

21. Seubwai W, Vaeteewoottacharn K, Hiyoshi M, Suzu S, Puapairoj A, Wongkham C, Okada S and Wongkham S: Cepharanthine exerts antitumor activity on cholangiocarcinoma by inhibiting NF-kappaB. Cancer Sci 101: 1590-1595, 2010.

22. Bailly C: Cepharanthine: An update of its mode of action, pharmacological properties and medical applications. Phytomedicine 62: 152956, 2019.

23. Tamatani T, Azuma M, Motegi K, Takamaru N, Kawashima Y and Bando T: Cepharanthin-enhanced radiosensitivity through the inhibition of radiation-induced nuclear factor-kappa B activity in human oral squamous cell carcinoma cells. Int J Oncol 31: 761-768, 2007.

24. Biswas KK, Tancharoen S, Sarker KP, Kawahara K, Hashiguchi T and Maruyama I: Cepharanthine triggers apoptosis in a human hepatocellular carcinoma cell line $(\mathrm{HuH}-7)$ through the activation of JNK1/2 and the downregulation of Akt. FEBS Lett 580: 703-710, 2006.

25. Rattanawong A, Payon V, Limpanasittikul W, Boonkrai C, Mutirangura A and Wonganan P: Cepharanthine exhibits a potent anticancer activity in p53-mutated colorectal cancer cells through upregulation of p21Waf1/Cip1. Oncol Rep 39: 227-238, 2018.

26. Hua P, Sun M, Zhang G, Zhang Y, Tian X, Li X, Cui R and Zhang $X$ : Cepharanthine induces apoptosis through reactive oxygen species and mitochondrial dysfunction in human non-small-cell lung cancer cells. Biochem Biophys Res Commun 460: 136-142, 2015.

27. Shi C, Huang D, Lu N, Chen D, Zhang M, Yan Y, Deng L, Lu Q, $\mathrm{Lu} \mathrm{H}$ and Luo S: Aberrantly activated Gli2-KIF20A axis is crucial for growth of hepatocellular carcinoma and predicts poor prognosis. Oncotarget 7: 26206-26219, 2016.

28. Xin M, Ji X, De La Cruz LK, Thareja S and Wang B: Strategies to target the Hedgehog signaling pathway for cancer therapy. Med Res Rev 38: 870-913, 2018.

29. Onishi $\mathrm{H}$ and Katano M: Hedgehog signaling pathway as a therapeutic target in various types of cancer. Cancer Sci 102: 1756-1760, 2011.

30. Girardi D, Barrichello A, Fernandes G and Pereira A: Targeting the hedgehog pathway in cancer: Current evidence and future perspectives. Cells 8: 153, 2019.

31. Infante $\mathrm{P}$, Alfonsi R, Botta $\mathrm{B}$, Mori M and Di Marcotullio L: Targeting GLI factors to inhibit the Hedgehog pathway. Trends Pharmacol Sci 36: 547-558, 2015.

32. Wang ZY and Chen Z: Differentiation and apoptosis induction therapy in acute promyelocytic leukaemia. Lancet Oncol 1: 101-106, 2000.

33. Lv XH, Wang CH and Xie Y: Arsenic trioxide combined with transarterial chemoembolization for primary liver cancer: A meta-analysis. J Gastroenterol Hepatol 32: 1540-1547, 2017. 
34. Owonikoko TK, Zhang G, Kim HS, Stinson RM, Bechara R, Zhang C, Chen Z, Saba NF, Pakkala S, Pillai R, et al: Patient-derived xenografts faithfully replicated clinical outcome in a phase II co-clinical trial of arsenic trioxide in relapsed small cell lung cancer. J Transl Med 14: 111, 2016.

35. Song Z, Wei B, Lu C, Huang X, Li P and Chen L: Metformin suppresses the expression of Sonic hedgehog in gastric cancer cells. Mol Med Rep 15: 1909-1915, 2017.

36. Fan C, Wang Y, Liu Z, Sun Y, Wang X, Wei G and Wei J: Metformin exerts anticancer effects through the inhibition of the Sonic hedgehog signaling pathway in breast cancer. Int J Mol Med 36: 204-214, 2015.

37. Nakamura M, Ogo A, Yamura M, Yamaguchi $Y$ and Nakashima H: Metformin suppresses sonic hedgehog expression in pancreatic cancer cells. Anticancer Res 34: 1765-1769, 2014.

38. Chatterjee S and Sil PC: Targeting the crosstalks of Wnt pathway with Hedgehog and Notch for cancer therapy. Pharmacol Res 142: 251-261, 2019.

39. Ding $M$ and Wang X: Antagonism between Hedgehog and Wnt signaling pathways regulates tumorigenicity. Oncol Lett 14 : 6327-6333, 2017.

40. Katoh Y and Katoh M: WNT antagonist, SFRP1, is Hedgehog signaling target. Int J Mol Med 17: 171-175, 2006.
41. Arnold KM, Pohlig RT and Sims-Mourtada J: Co-activation of Hedgehog and Wnt signaling pathways is associated with poor outcomes in triple negative breast cancer. Oncol Lett 14: 5285-5292, 2017.

42. Anastas JN and Moon RT: WNT signalling pathways as therapeutic targets in cancer. Nat Rev Cancer 13: 11-26, 2013.

43. Kikukawa Y, Okuno Y, Tatetsu H, Nakamura M, Harada N, Ueno S, Kamizaki Y, Mitsuya $\mathrm{H}$ and Hata H: Induction of cell cycle arrest and apoptosis in myeloma cells by cepharanthine, a biscoclaurine alkaloid. Int J Oncol 33: 807-814, 2008.

44. Lyu J, Yang EJ, Head SA, Ai N, Zhang B, Wu C, Li RJ, Liu Y, Yang C, Dang Y, et al: Pharmacological blockade of cholesterol trafficking by cepharanthine in endothelial cells suppresses angiogenesis and tumor growth. Cancer Lett 409: 91-103, 2017.

45. Harada T, Harada K and Ueyama Y: The enhancement of tumor radioresponse by combined treatment with cepharanthine is accompanied by the inhibition of DNA damage repair and the induction of apoptosis in oral squamous cell carcinoma. Int J Oncol 41: 565-572, 2012.

This work is licensed under a Creative Commons Attribution-NonCommercial-NoDerivatives 4.0 International (CC BY-NC-ND 4.0) License. 